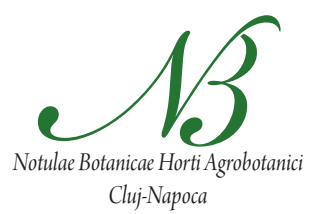

\title{
Increased Tolerance of Citrus (Citrus tangerina) Seedlings to Soil Water Deficit after Mycorrhizal Inoculation: Changes in Antioxidant Enzyme Defense System
}

\author{
Qiu-Dan NI, Ying-Ning ZOU*, Qiang-Sheng WU*, Yong-Ming HUANG \\ Yangtze University, College of Horticulture and Gardening, No 88 Jingmi Raod, Jingzhou, Hubei 434025, China; zouyingning@163.com
}

(*orresponding author)

\begin{abstract}
Arbuscular mycorrhizal fungi (AMF) can enhance tolerance of plants to soil water deficit, whereas morphological observations of reactive oxygen species and antioxidant enzyme system are poorly studied. The present study thereby evaluated temporal variations of the antioxidant enzyme system in citrus (Citrus tangerina) seedlings colonized by Glomus etunicatum and G. mosseae over a 12-day period of soil drying. Root colonization by G. etunicatum and G. mosseae decreased with soil drying days from 32.0 to $1.0 \%$ and 50.1 to $4.5 \%$ in 0-day to 12-day, respectively. Compared to the non-AM controls, the AMF colonized plants had significantly lower tissue (both leaves and roots) hydrogen peroxide $\left(\mathrm{H}_{2} \mathrm{O}_{2}\right)$ and superoxide anion radical $\left(\mathrm{O}_{2}{ }^{-}\right)$concentrations during soil water deficit, whereas 1.03-1.92, 1.25-1.84 and 1.18-1.69 times higher enzyme activity in superoxide dismutase, peroxidase (POD) and catalase. In situ leaf $\mathrm{H}_{2} \mathrm{O}_{2}$ and root POD location also showed that AM seedlings had less leaf $\mathrm{H}_{2} \mathrm{O}_{2}$ but higher root POD accumulation. Furthermore, significantly higher root infection and antioxidant enzymatic activities in plants colonized with G. mosseae expressed than with G. etunicatum during the soil drying. These results demonstrated that the AMs could confer greater tolerance of citrus seedlings to soil water deficit through an enhancement in their antioxidant enzyme defence system whilst an decrease level in $\mathrm{H}_{2} \mathrm{O}_{2}$ and $\mathrm{O}_{2}^{--}$.
\end{abstract}

Keywords: Glomus mosseae, hydrogen peroxide, mycorrhiza, peroxidase, reactive oxygen species, superoxide dismutase

\section{Introduction}

Drought, one of the major environmental stresses, adversely restricts crop growth and yield. The damage effects of soil water deficit (SWD) include arrays of morphological, physiological, biochemical and molecular changes (Wang et al., 2001). Meanwhile, SWD often causes oxidative stress, which imposes the origin reaction of reactive oxygen species (ROS), such as hydrogen peroxide $\left(\mathrm{H}_{2} \mathrm{O}_{2}\right)$ and superoxide anion radical $\left(\mathrm{O}_{2}^{-{ }^{-}}\right)$. The production and scavenging of ROS are kept in a dynamical balance under well-watered conditions, whereas SWD can break this balance and induce greater accumulation of ROS, thereby triggering the damages to the membranes, DNA, and proteins (Impa and Nadaradjan, 2012). On the other hand, plants also develop an antioxidant enzyme defense system including catalase (CAT), peroxidase (POD), and superoxide dismutase (SOD) (Mohammadi et al., 2011) and non-enzymatic antioxidant defense system such as ascorbate (AsA) and glutathione (GSH) (Pyngrope et al., 2013) to decrease the oxidative damage. Meanwhile, these antioxidant enzymes act the important functions to scavenge or detoxify the excess ROS under drought stress (Sharma et al., 2012). In general, POD scavenges different substrates at the cost of $\mathrm{H}_{2} \mathrm{O}_{2}$, SOD decomposes $\mathrm{O}_{2}{ }^{--}$to $\mathrm{O}_{2}$ and $\mathrm{H}_{2} \mathrm{O}_{2}$, and CAT detoxifies $\mathrm{H}_{2} \mathrm{O}_{2}$ (Pyngrope et al., 2013).
Arbuscular mycorrhizal fungi (AMF), one of the most widespread endophytic microorganisms, can form mutualistic symbiosis, arbuscular mycorrhizas (AMs), with the roots of $80 \%$ higher plants. It has been demonstrated that the AM symbiosis can protect plants against SWD, such as Chlorophytum borivilianum (Sushma and Tarafdar, 2012), chickpea (Sohrabia et al., 2012), and Knautia arvensis (Pavla et al., 2013). Our previous study showed that AM-induced better growth and higher soil phosphatase activity was the basis for enhancing tolerance of trifoliate orange to SWD (Wu et al., 2011). Studies have proved that the SOD activity of lettuce inoculated with Glomus mosseae was significantly higher than the un-inoculated plants under drought (Ruiz-Lozano et al., 1996). Tian et al. (2013) showed that the Plukenetia volubilis plants colonized by $G$. versiforme increased guaiacol peroxidase (G-POD) and CAT activities, thus reducing the damage caused by ROS accumulation under drought. The Allium sativum plants colonized by $G$. fasciculatum had markedly higher leaf SOD and CAT and root POD activities under SWD, compared with the non-AMF colonized controls (Borde et al., 2012). Wu et al. (2006) also reported that AMF significantly increased leaf POD and glutathione reductase activities and root ascorbate peroxidase activity in trifoliate orange seedlings exposed to SWD. These studies fully displayed that the antioxidant enzyme defense system can act an important mechanism to enhance tolerance 
of the host plant to SWD under mycorrhization, but no information involved in the temporal variations of antioxidant enzyme system. Although the AM-induced tolerance to SWD also involves in nutrient uptake, extraradical hyphae, root system architecture, glomalin, osmoregulation, and antioxidant defense systems (Wu et al., 2013), whereas the information about the morphological observation of ROS and antioxidant enzymes is lacking under mycorrhization. On the other hand, our previous studies are mainly paid great attention to antioxidant enzyme activities after a certain time period of soil drought (Wu et al., 2006, 2007), while little is paid to the dynamic change of antioxidant enzymes caused by AMF over a period of soil drying.

Citrus, an important evergreen fruit tree, is cultivated in many countries around the world. Meanwhile, China is one of the main citrus fruit-producing countries and has reached to $\sim 2.3$ million hectares of citrus plantation in 2011 with an annual $3 \%$ increase in recent five years. However, citrus trees in China are often facing severe soil drying, particularly during summer. The object of this study was thus to evaluate the dynamic change of antioxidant enzyme defense systems in citrus plants inoculated with or without G. mosseae and G. etunicatum over a 12 days period of soil drying. Furthermore, this study also analyzed the in situ morphological changes through leaf $\mathrm{H}_{2} \mathrm{O}_{2}$ and root POD location.

\section{Materials and methods}

\section{Plant culture}

Seeds of red tangerine (Citrus tangerina Hort. ex Tana$\mathrm{ka}$ ), collected from a Citrus Orchard of Yangtze University campus, were sowed on March 27, 2010. Before sowing, seeds were disinfected for $5 \mathrm{~min}$ in $5 \% \mathrm{H}_{2} \mathrm{O}_{2}$, rinsed four times with distilled water, and sown into a $15 \times 18 \times 20 \mathrm{~cm}$ plastic pot containing the autoclaved $\left(0.11 \mathrm{MPa}, 121^{\circ} \mathrm{C}\right.$, $2 \mathrm{~h}$ ) substrates of yellow soil, vermiculite, and sphagnum $(2: 1: 1, \mathrm{v} / \mathrm{v} / \mathrm{v})$. At sowing, seedlings for the AM inoculation received $50 \mathrm{~g} \mathrm{AM}$ inocula including the infected roots of Sorghum vulgare, spores, and external hyphae, and the non-inoculated seedlings received same quantity autoclaved inoculants as the control. All the AM and non-AM seedlings were watered with deionized water at an interval of 3 days to keep field capacity, based daily evaporation rate. The seedlings were placed in a plastic greenhouse of Yangtze University, where day/night temperature was $24 / 18^{\circ} \mathrm{C}$, relative humidity $70-95 \%$, and photosynthetic photon flux density $672-893 \mu \mathrm{mol} / \mathrm{m}^{2} / \mathrm{s}$.

\section{Experimental design}

The experiment consisted of a two-factor randomized design with three AMF inoculations (G. mosseae, G. etunicatum, and non-AMF control) and stressed days of SWD $(0,4,8,12$ days). Each treatment replicated three times, and each replicate contained three seedlings, for a total of
36 pots or replicates. Meanwhile, before the SWD, all the pots were uniformly watered to field capacity $(-0.02 \mathrm{Mpa}$, soil water potential) by weighting in terms of daily evaporation rate for 24 weeks and then subjected to a continuous soil drying episode by withholding water of pots for 12 days.

\section{Measurement of root colonization}

Root mycorrhizal colonization was done following the method of Phillips and Hayman (1970).

\section{Determinations of antioxidant enzymes and ROS}

Analysis of SOD was accorded to Giannopolitis and Ries (1977). CAT and POD activities were measured using the method of Aebi (1984) and Kar and Mishar (1976), respectively.

The concentrations of $\mathrm{H}_{2} \mathrm{O}_{2}$ and $\mathrm{O}_{2}{ }^{--}$were measured as Harinasut et al. (2003) and Wu et al. (2006), respectively.

\section{Leaf $\mathrm{H}_{2} \mathrm{O}_{2}$ location in situ}

Leaf $\mathrm{H}_{2} \mathrm{O}_{2}$ location in situ was followed by RomeroPuertas et al. (2004) with minor modifications. Briefly, intact leaves were rapidly immersed in 1\% Diaminobenzidine (DAB) contained in $10 \mathrm{mM}$ MES buffer ( $\mathrm{pH}$ 6.5), vacuum-infiltrated for $30 \mathrm{~min}$, and then incubated in darkness at ambience for $8 \mathrm{~h}$. Subsequently, the leaf was illuminated until the appearance of brown spots which was caused by the reaction of $\mathrm{DAB}$ and $\mathrm{H}_{2} \mathrm{O}_{2}$, and then bleached by immersing in $95 \%$ ethanol to visualize the brown spots. Afterwards, the leaf was immersed in distilled water and visualized the bronzing precipitates.

\section{Root POD location in situ}

Root POD location in situ was determined according to the method of Thordal-Christensen et al. (1997) and Salzer et al. (1999) with minor modifications. Fresh AM and non-AM root segments at 12 days of soil drying were incubated in $1 \mathrm{mg} \mathrm{mL}^{-1} \mathrm{DAB}$ for $15 \mathrm{~min}$, immersed in $0.1 \mathrm{mM} \mathrm{H}_{2} \mathrm{O}_{2}$ for $2 \mathrm{~min}$, and ended by $96 \%$ ethanol. The roots then were transferred to $10 \%$ lactic acid solution for microscopic examination.

\section{Statistical analysis}

Experimental data were analyzed using variance (ANOVA) with the SAS software. Fisher's Protected Least Significant Differences were used to compare the significant differences at $5 \%$ level.

\section{Results}

Root mycorrhizal colonization ranged from 50.1 to $4.5 \%$ under G. mosseae and from 32.0 to $1.0 \%$ under $G$. etunicatum during $0-12$ days of soil drying (Fig. 1). Root mycorrhizal colonization notably decreased with the increase of soil drying days, and $t$ was significantly higher in 
526

the $G$. mosseae-colonized seedlings than in the $G$. etunicatum seedlings during the soil drying.

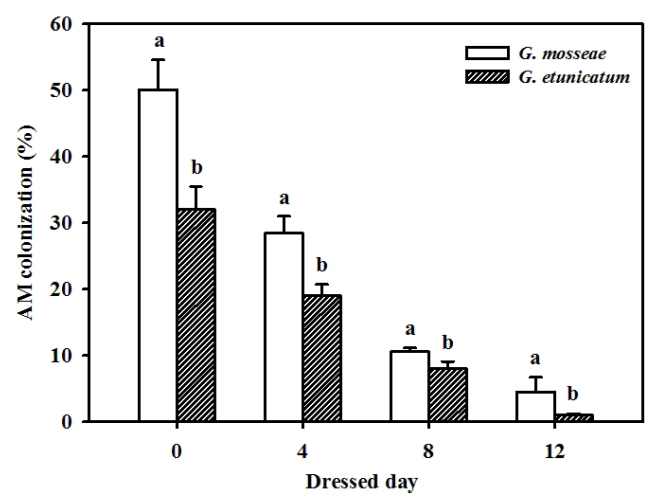

Fig. 1. Effect of soil drying on root mycorrhizal colonization of Citrus tangerina plants. Different letters above the bars between AMF treatments under similar days of soil drying indicated significant differences at $5 \%$ level

Leaf $\mathrm{H}_{2} \mathrm{O}_{2}$ in situ showed the significant differences between $\mathrm{AM}^{2}$ and non-AM seedlings under 0-12 days of soil drying (Fig. 2). The quantity of brown spots in leaves increased with the increase of soil drying days, irrespective of AM and non-AM seedlings. At 0, 4, 8, and 12 days of soil drying, the plants with G. mosseae and G. etunicatum showed less brown spots than non-AM plants. In addition, the AM seedlings had only a few brown precipitates that were associated with the mesophyll part even at the later stage of SWD. However, the precipitates in the nonAM plants caused by $\mathrm{H}_{2} \mathrm{O}_{2}$ accumulation gradually spread from mesophyll and principal vein to whole leaf.

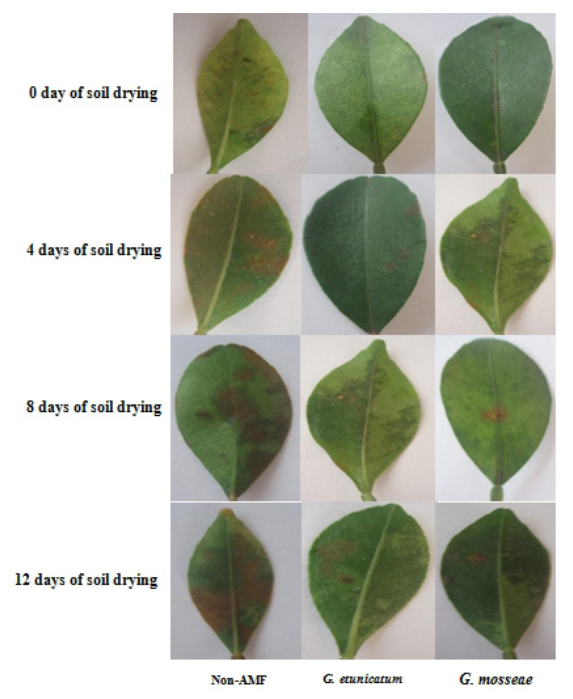

Fig. 2. Leaf $\mathrm{H}_{2} \mathrm{O}_{2}$ location in situ of Citrus tangerina plants colonized by Glomus mosseae, G. etunicatum and non-AMF at a 12-days of soil drying. The brown precipitates indicate $\mathrm{H}_{2} \mathrm{O}_{2}$ accumulation.

During the 12 days of soil drying, leaves and roots in the
G. mosseae and G. etunicatum seedlings had less $\mathrm{H}_{2} \mathrm{O}_{2}$ (Fig. 3) and $\mathrm{O}_{2}^{-}$(Fig. 4) concentrations than these in the nonAM seedlings. Meanwhile, the concentration of $\mathrm{H}_{2} \mathrm{O}_{2}$ and $\mathrm{O}_{2}{ }^{-}$in leaves and roots were highest in non-AM treatment, higher in G. etunicatum and least in G. mosseae.

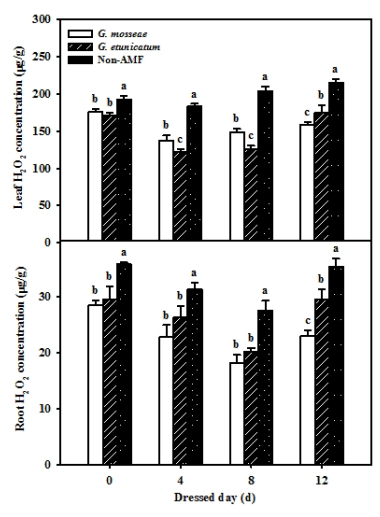

Fig. 3. Effect of soil drying and AMF on leaf and root $\mathrm{H}_{2} \mathrm{O}_{2}$ concentrations of Citrus tangerina plants. Different letters above the bars among AMF treatments under similar days of soil drying indicated significant differences at $5 \%$ level

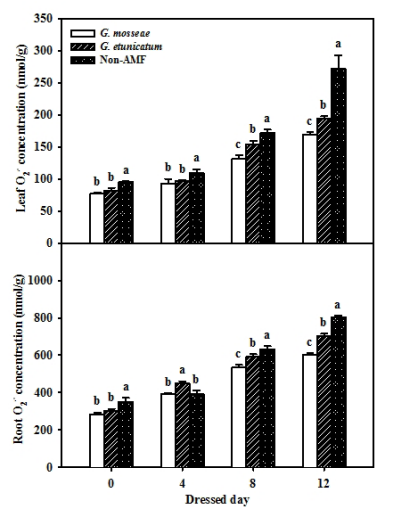

Fig. 4. Effect of soil drying and AMF on leaf and root $\mathrm{O}_{2}{ }^{--}$concentrations of Citrus tangerina plants. Different letters above the bars among AMF treatments under similar days of soil drying indicated significant differences at $5 \%$ level

Generally, SWD caused an obvious decline in CAT activity of leaves or roots, irrespective of AM colonized or not (Fig. 5). Meanwhile, the CAT activity in roots and leaves were significantly higher in mycorrzhial plants than in non-mycorrhizal ones, irrespectively of soil drying days. The leaf or root CAT activity of G. mosseae-colonized seedlings was significantly higher than that of G. etunicatum-colonized seedlings.

Leaf and root POD activity increased with the increase of soil drying days (Fig. 6). On the other hand, AM seedlings had significantly higher leaf and root POD activity than non-AM seedlings, regardless of soil water status. Meanwhile, G. mosseae showed better effects on leaf and root POD activity than G. etuncatum. Compared with the non-AMF treatment, the situ localization of POD in root in the G. mosseae and G. etunicatum treatments showed 
lower brown root staining (Fig. 7). In addition, the root brown staining was significantly different between G. mosseae- and G. etunicatum-colonized roots.

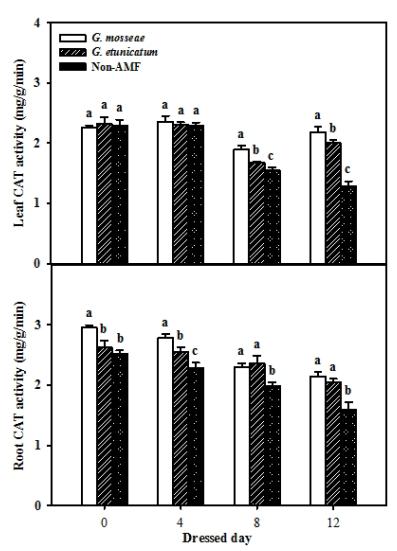

Fig. 5. Effect of soil drying and AMF on leaf and root CAT activity of Citrus tangerina plants. Different letters above the bars among AMF treatments under similar days of soil drying indicated significant differences at $5 \%$ level

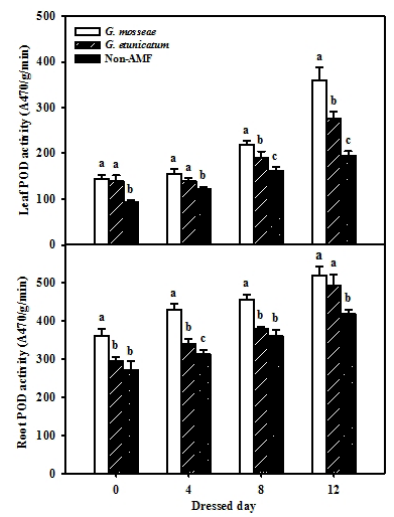

Fig. 6. Effect of soil drying and AMF on leaf and root POD activity of Citrus tangerina plants. Different letters above the bars among AMF treatments under similar days of soil drying indicated significant differences at $5 \%$ level
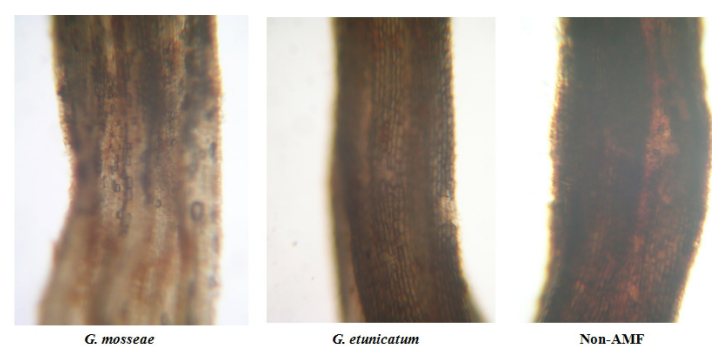

Fig. 7. Root POD location in situ of Citrus tangerina plants colonized by Glomus mosseae, G. etunicatum and non-AMF after 12 days of soil drying. The brown staining of roots showed the accumulation of $\mathrm{H}_{2} \mathrm{O}_{2}$

At 0 days of SWD, AM inoculation did not affect leaf SOD activity but enhanced root SOD activity (Fig. 8). At 4 days of SWD, AMF colonization did not affect root
SOD activity but increased leaf SOD activity. At 8 and 12 days of SWD, AMs significantly increased leaf and root SOD activity.

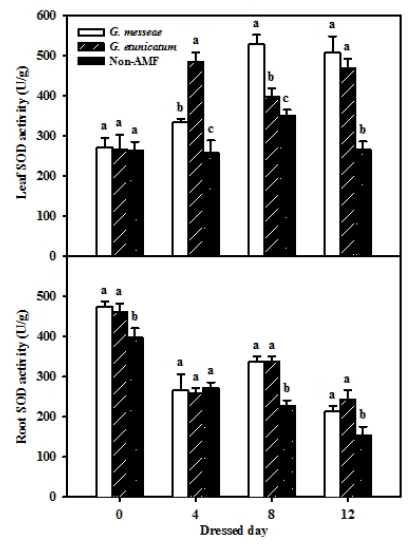

Fig. 8. Effect of soil drying and AMF on leaf and root SOD activity of Citrus tangerina plants. Different letters above the bars among AMF treatments under similar days of soil drying indicated significant differences at $5 \%$ level

\section{Discussion}

Under soil water deficit AM symbiosis generally confers better growth performance, greater photosynthetic efficiency, and higher antioxidant system defense systems of host plants, including bean, wheat, and rice plants (Habibzadeh et al., 2013; Moucheshi et al., 2012; RuizSánchez et al., 2010). Our study also indicated that the AMF inoculations presented higher activities of tissue SOD, POD, and CAT during SWD, in company with lower levels of $\mathrm{H}_{2} \mathrm{O}_{2}$ and $\mathrm{O}_{2}^{--}$, although root mycorrhizal colonization decreased with timing of SWD. This is consistent with the findings of Wu and Zou (2009), who reported that mycorrhizal grafted citrus seedlings had significantly lower $\mathrm{H}_{2} \mathrm{O}_{2}$ and $\mathrm{O}_{2}^{--}$and higher activities of SOD, POD, and CAT under SWD. This suggested that AMs might enhanced drought tolerance of the host plant by increasing antioxidant enzyme activities to reduce ROS concentration.

In the present study, $\mathrm{H}_{2} \mathrm{O}_{2}$ and $\mathrm{O}_{2}^{--}$concentrations were higher in the non-AM seedlings than in the AM seedlings, indicating that AM seedlings during SWD suffered from less oxidative damage than non-AM controls. Such less oxidative damage in AM seedlings might be due to that AM associations could confer better water availability and osmoregulation defense mechanism and higher antioxidant defense systems (Porcel and Ruiz-Lozano, 2004; Wu et al., 2013). Fester and Hause (2005) found that the intracellular accumulation of $\mathrm{H}_{2} \mathrm{O}_{2}$ was located on the surface of fungal hyphae and diffused in the thin hyphal wall of arbuscule branches, thereby resulting in the fungal programme for senescence. It seemed that AMs partly accumulated $\mathrm{H}_{2} \mathrm{O}_{2}$ in hyphae and arbuscules, thereby alleviating oxidative damage in other cells of AM roots 
528

(Fester and Hause, 2005). On the other hand, the decrease of $\mathrm{H}_{2} \mathrm{O}_{2}$ and $\mathrm{O}_{2}{ }^{--}$caused by mycorrhization might dependent on AMF specie, as $G$. mosseae exhibited better effects on decreasing of WHAT than G. etunicatun during soil drying. This result is in agreement with the finding of Wu et al. (2007). The in situ location of leaf $\mathrm{H}_{2} \mathrm{O}_{2}$ also showed that brown spots in leaves were less in the AM than in the non-AM seedlings during soil drying, suggesting that AMs obviously decreased the accumulation of $\mathrm{H}_{2} \mathrm{O}_{2}$ in leaf.

Yin et al. (2010) showed that SOD activity of nonAM strawberry was significantly lower than that of AM plants. Our study proved that the activity of root and leaf SOD was generally significantly higher in mycorrhizal than in non-mycorrhizal plants during soil drying. This is in agreement with the findings of Zhu et al. (2011) in $G$. etunicatum-inoculated maize under four weeks of SWD. Since SOD enzymes possess detoxification capacity by catalyzing $\mathrm{O}_{2}^{--}$to $\mathrm{H}_{2} \mathrm{O}_{2}$ (Xu et al., 2013), the higher SOD activity in the AM seedlings could remove more $\mathrm{O}_{2}^{--}$, thus conferring less damage of $\mathrm{O}_{2}{ }^{\bullet-}$.

It is well known that POD oxidizes different substrates at the cost of $\mathrm{H}_{2} \mathrm{O}_{2}$ (Pyngrope $e t$ al., 2013). In the present study, the AM seedlings had significantly higher leaf and root $\mathrm{POD}$ activities than non-AM seedlings during soil drying, which is consistent with the results of pistachio plants colonized by G. etunicatum fungi under DS (Abbaspour et al., 2012). In addition, G. mosseae was better than G. etunicatun in increasing POD activity of the citrus seedlings under SWD. In the morphological observation, our study showed that after 12 days of soil drying, AM roots exhibited lower brown staining than the non-AM roots, suggesting that a higher POD activity in AM roots resulted in a lower accumulation of $\mathrm{H}_{2} \mathrm{O}_{2}$. The DAB staining in roots could reflect an accumulation of $\mathrm{H}_{2} \mathrm{O}_{2}$, which is in agreement with the finding of Salzer et al. (1999). As a result, mycorrhizal citrus seedlings that possess significantly higher POD activity could cope with ROS accumulation during soil drying.

CAT can detoxify the $\mathrm{H}_{2} \mathrm{O}_{2}$ to $\mathrm{H}_{2} \mathrm{O}$ and $\mathrm{O}_{2}$ (MoraHerrera et al., 2012). Huang et al. (2010) proved that AMs had little effect on CAT in tomato roots but significantly increased leaf CAT under salt stress. Wu et al. (2010) also found notably higher activity of CAT in trifoliate orange plants colonized by $G$. mosseae and G. versiforme under salt stress. Our study showed that the AMs did not significantly affect leaf CAT activity at 0 and 4 days of soil drying but notably increased leaf CAT activity at 8 and 12 days of soil drying, suggesting that the inducing of CAT activity caused by AMF was dependent on the time of drought stress. Thus, at the beginning of SWD, CAT did not act its ROS elimination role in leaves of AM plants. In contrast, AM roots had higher CAT activity than the non-AM roots, implying that during SWD, root CAT might be induced by AMF colonization. Higher CAT activity of AM seedlings could thus confer their host plant to detoxify more $\mathrm{H}_{2} \mathrm{O}_{2}$ accumulation, resulting in lower oxidative damage.

\section{Conclusion}

In the present work, G. mosseae and G. etunicatum had positive effects on antioxidant enzyme defense systems in leaf and root of $C$. tangerina seedlings grown under SWD, thereby decreased the $\mathrm{H}_{2} \mathrm{O}_{2}$ and $\mathrm{O}_{2}{ }^{--}$concentrations of citrus tissues. As a result, AMs conferred greater drought tolerance to citrus seedlings during SWD in terms of a higher antioxidant enzyme defense system.

\section{Acknowledgements}

This study was supported by the National Natural Science Foundation of China (31101513) and the Excellent Young Teacher Research Support Program of Yangtze University (cyq201326). Here, we sincerely thank Dr. Xin-Hua He at the University of Western Australia to polish the language of the paper.

\section{References}

Abbaspour H, Saeidi-Sar S, Afshari H, Abdel-Wahhab MA (2012). Tolerance of mycorrhiza infected pistachio (Pistacia vera $\mathrm{L}$.) seedling to drought stress under glasshouse conditions. J Plant Physiol 169:704-709.

Aebi H (1984). Catalase in vitro. Method Enzymol 105:121126.

Borde M, Dudhane M, Jite P (2012). Growth, water use efficiency and antioxidant defense responses of mycorrhizal and non mycorrhizal Allium sativum L. under drought stress condition. Ann Plant Sci 1(1):6-11.

Fester T, Hause G (2005). Accumulation of reactive oxygen species in arbuscular mycorrhizal roots. Mycorrhiza 15:373 379.

Giannopolitis CN, Ries SK (1977). Superoxide dismutase. I. Occurrence in higher plants. Plant Physiol 59:309-314.

Habibzadeh Y, Pirzad A, Zardashti MR, Jalilian J, Eini O (2013). Effects of arbuscular mycorrhizal fungi on seed and protein yield under water-deficit stress in mung bean. Agron J 105(1):79-84

Harinasut P, Poonsopa D, Roengmongkol K, Charoensataporn R (2003). Salinity effects on antioxidant enzymes in mulberry cultivar. Science Asia 29:109-113.

Huang Z, He CX, He ZQ, Zou ZR, Zhang ZB (2010). The Effects of arbuscular mycorrhizal fungi on reactive oxyradical scavenging system of tomato under salt tolerance. Agric Sci Chin 9:1150-1159.

Impa SM, Nadaradjan S, Jagadish SVK (2012). Drought stress induced reactive oxygen species and antioxidants in plants, p. 131-147. In: Ahmad P, Prasad MNV (Eds.). Abiotic stress responses in plants. Springer-Verlag. Press, New York.

Kar M, Mishra D (1976). Catalase, peroxidase, and polyphe- 
noloxidase activities during rice leaf senescence. Plant Physiol 57:315-319.

Mora-Herrera ME, López-Delgado H, Valadez-Moctezuma E, Scott IM (2012). Changes in hydrogen peroxide levels and catalase isoforms expression are induced with freezing tolerance by abscisic acid in potato microplants (99-112). In: Lushchak VI (Ed.). Oxidative Stress-Environ Induction and Dietary Antioxidants. InTech. Press, Rijeka,Croatia.

Mohammadi A, Habibi D, Rohami M, Mafakheri S (2011). Effect of drought stress on antioxidant enzymes activity of some chickpea cultivars. Amer-Eur J Agric Environ Sci 11:782-785.

Moucheshi A, Heidari B, Assad MT (2012). Alleviation of drought stress effects on wheat using arbuscular mycorrhizal symbiosis. Int J Agrisci 2:35-47.

Pavla D, Eva V, Radka S (2013). Arbuscular mycorrhizal symbiosis alleviates drought stress imposed on knautia arvensis plants in serpentine soil. Plant Soil 370:149.

Phillips JM, Hayman DS (1970). Improved procedures for clearing roots and staining parasitic and vesicular-arbuscular mycorrhizal fungi for rapid assessment of infection. Trans Brit Mycol Soc 55:158-161.

Porcel R, Ruiz-Lozano JM (2004). Arbuscular mycorrhizal influence on leaf water potential, solute accumulation, and oxidative stress in soybean plants subjected to drought stress. J Exp Bot 55:1743-1750.

Pyngrope S, Bhoomika K, Dubey RS (2013). Reactive oxygen species, ascorate-glutathione pool, and enzymes of their metabolism in drought-sensitive and tolerant indica rice (Oryza sativa L.) seedlings subjected to progressing levels of water deficit. Protoplasma 250:585-600.

Ruiz-Sánchez M, Aroca R, Muñoz Y, Polón R, Ruiz-Lozano JM (2010). The arbuscular mycorrhizal symbiosis enhances the photosynthetic efficiency and the antioxidative response of rice plants subjected to drought stress. J Plant Physiol 167:862-869.

Ruiz-Lozano JM, Azcón R, Palma JM (1996). Superoxide dismutase activity in arbuscular mycorrhizal Lactuca sativa plants subjected to drought stress. New Phytol 134:327333.

Romero-Puertas MC, Rodríguez-Serrano M, Corpas FJ, Gómez M, Delrío LA, Sandalio LM (2004). Cadmium-induced subcellular accumulation of $\mathrm{O}_{2}^{\cdot-}$ and $\mathrm{H}_{2} \mathrm{O}^{2}$ in pea leaves. Plant Cell Environ 27:1122-1134.

Salzer P, Corbière H, Boller T (1999). Hydrogen peroxide accumulation in Medicago truncatula roots colonized by the arbuscular mycorrhiza-forming fungus Glomus intraradices. Planta 208:319-325.

Sohrabia Y, Heidaria G, Weisany W, Ghasemi-Golezani K, Mohammadi K (2012). Some physiological responses of chickpea cultivars to arbuscular mycorrhiza under drought stress. Russ J Plant Physiol 59(6):708-716.

Sharma P, Pessarakli M, Dubey RS, Jha AB (2012). Reactive
529

oxygen species, oxidative damage, and antioxidative defense mechanism in plants under stressful conditions. J Bot doi: $10.1155 / 2012 / 217037$.

Sushma D, Tarafdar JC (2012). Arbuscular mycorrhizal fungi encourage drought tolerance of Chlorophytum borivilianum by enhancing antioxidant enzyme system. Biol Res 14(1):6070 .

Thordal-Christensen H, Zhang ZG, Wei YD, Collinge DB (1997). Subcellular localization of $\mathrm{H}_{2} \mathrm{O}_{2}$ in plants: $\mathrm{H}_{2} \mathrm{O}_{2}$ accumulation in papillae and hypersensitive response during the barley-powdery mildew interaction. Plant J 11:11871194.

Tian YH, Lei YB, Zheng YL, Cai ZQ (2013). Synergistic effect of colonization with arbuscular mycorrhizal fungi improves growth and drought tolerance of Plukenetia volubilis seedlings. Acta Physiol Plant 35:687-696.

Wang WX, Vinocur B, Shoseyov O, Altman A (2001). Biotechnology of plant osmotic stress tolerance: physiological and molecular considerations. Acta Hort 560:285-292.

Wu QS, Srivastava AK, Zou YN (2013). AMF-induced tolerance to drought stress in citrus: A review. Sci Hortic 164:7787.

Wu QS, Zou YN, Xia RX (2006). Reactive oxygen metabolism in mycorrhizal and non-mycorrhizal citrus (Poncirus trifoliata) seedlings subjected to water stress. J Plant Physiol 163:1101-1110.

Wu QS, Zou YN, Xia RX, Wang MY (2007). Five Glomus species affect water relations of Citrus tangerine during drought stress. Bot Stud 48:147-154.

Wu QS, Zou YN (2009). Mycorrhiza has a direct effect on reactive oxygen metabolism of drought-stressed citrus. Plant Soil Environ 55:436-442.

Wu QS, Zou YN, Liu W, Ye XF, Zai HF, Zhao LJ (2010). Alleviation of salt stress in citrus seedlings inoculated with mycorrhiza: changes in leaf antioxidant defense systems. Plant Soil Environ 56: 470-475.

Wu QS, Zou YN, He XH (2011). Differences of hyphal and soil phosphatase activities in drought-stressed mycorrhizal trifoliate orange (Poncirus trifoliata) seedlings. Sci Hortic 129:294-298.

Xu J, Duan XG, Yang J, Beeching JR, Zhang P (2013). Enhanced reactive oxygen species scavenging by overproduction of superoxide dismutase and catalase delays postharvest physiological deterioration of cassava storage roots. Plant Physiol 161:1517-1528.

Yin BZ, Wang YN, Liu P, Hu JL, Zhen WC (2010). Effects of vesicular-arbuscular mycorrhiza on the protective system in strawberry leaves under drought stress. Front Agric China 4:165-169.

Zhu XC, Song FB, Liu SQ (2011). Arbuscular mycorrhiza impacts on drought stress of maize plants by lipid peroxidation, proline content and activity of antioxidant system. J Food Agric Environ 9:583-587. 